\title{
Counting absolute numbers of items, from 1 to 8, in pigeons
}

\author{
Shin Hirai and Masako Jitsumori \\ Chiba University, Chiba, Japan
}

\begin{abstract}
Pigeons were trained in a forced choice task with four alternatives to categorize arrays consisting of $1,3,5$, or 8 dots. Before the pigeons chose a comparison stimulus, they were required to peck each dot sequentially. A single peck to a dot, which was defined as an indicating response, changed the color of the dot so that it was differentiated from those that remained to be counted. The pigeons successfully learned to categorize the numerical arrays and then displayed transfer to novel arrays consisting of two, four, six, or seven dots, in a manner according to the order of $1<2<3<4<5<6<7<8$. Subsequent tests revealed that the pigeons discriminated the stimuli by relying on the number of indicating responses. They also utilized multiple information (surface area, time, and other confounded events), but this was of minor significance, and after training, the pigeons were able to disregard these cues.
\end{abstract}

When objects are counted-for example, coinssometimes, every coin is individually moved from an uncounted set to a counted set. Such an act helps to apply a unique cardinal tag in one-to-one correspondence to each item, by separating items that have already been counted and those that remain (Gelman \& Gallistel, 1978). Indicating acts, such as partitioning and tagging, are often observed in children during numerical problem solving (Fuson, 1988). Partitioning is the distinction between items to be counted and those already counted. Tagging is the response that applies a distinct tag or symbol to each item in the array. Indicating acts by birds were anecdotally reported in the early studies of Koehler (e.g., 1950). He suggested that the voluntary movements displayed by animals to each item in an array may reflect inner markings for the items that they have seen. More recently, indicating acts were observed with laboratory animals performing in counting tasks in which food or food-related items were used as stimuli. Boysen, Berntson, Shreyer, and Hannan (1995) reported the indicating acts (pointing, touching, and rearranging items) of a chimpanzee that had been trained to select the placard with the correct Arabic numeral that corresponded to the size (0-7) of a candy array. The indicating acts that were displayed without explicit training were considered to represent covert tagging behavior by the animal. Suzuki and Kobayashi (2000) reported that rats trained with a counting task that simulated foraging (see Davis \& Bradford, 1986) displayed so-called intentional acts (e.g., Chen, 1967), such as bowing or head turning, to each box in an array. These acts were performed more frequently on correct trials than on error trials. They argued that rats might use numerical representations to solve a counting problem.
It has been repeatedly argued that counting requires the use of a numerical representation that has the properties of ordinality and cardinality (e.g., Davis \& Memmott, 1982; Gelman \& Gallistel, 1978). The tags must be applied in a consistent order, with the last tag representing the numerosity of the set. So counting involves the ability to judge absolute, or cardinal, numerical amounts or numbers of responses (Emmerton, 2001). Davis and Memmott argued that, in infrahumans, counting is a relatively unnatural response that may require considerable environmental support. Davis and Pérusse (1988) further argued that animal numerical discrimination can be explained by subitizing, or some equally primitive process, rather than counting (but see Capaldi \& Miller, 1988). By contrast, Gelman and Gallistel suggested that animals might assign items in a series to successive states of an internal neural process. They termed these successive states numerons and proposed that they function as number tags. Whether animals count absolute number of items and translate the numerosity into a numerical representation remains controversial.

It has been well documented that some animals-for example, pigeons, rats, and monkeys - have the ability to discriminate relative differences in number (e.g., Alsop \& Honig, 1991; Emmerton, 1998; Emmerton, Lohmann, \& Niemann, 1997; Fernandes \& Church, 1982; Fetterman, 1993; Roberts \& Boisvert, 1998; Roberts, Macuda, \& Brodbeck, 1995; Roberts \& Mitchell, 1994; Thomas, Fowlkes, \& Vickery, 1980) and to emit a certain number of responses depending on the symbols arbitrarily assigned to the numbers (e.g., Platt \& Johnson, 1971; Xia, Siemann, \& Delius, 2000). However, the ability to associate arbitrary symbols with absolute numbers of items in

M. Jitsumori, mjitsu@1.chiba-u.ac.jp 
stimulus arrays has mostly been demonstrated in primates (e.g., Boysen et al., 1995; Matsuzawa, 1985) and an African Grey parrot (Pepperberg, 1994). An exception is the study of Xia, Emmerton, Siemann, and Delius (2001), which reported that pigeons have this ability.

In the study of Xia et al. (2001), pigeons were trained to choose the symbol that corresponded to the preceding number of red-filled circles (one, two, three, four, or five) in an array, after first responding to each circle that initially bore a small central black dot. A single peck to each circle produced a brief tone and also removed the black dot from the circle. The pigeons successfully discriminated the absolute number of items in spite of variation in the characteristics of the stimuli-for example, the shape, size, and configuration of the items (thus, meeting the abstraction principle), and of the location of the symbols representing the numerosity. The pigeons' discriminative performance for a numerosity above 2 was severely disrupted in a test in which they were allowed to peck only a single item before they chose a symbol. This finding suggested that the number of pecks issued to each display was critical for the pigeons to discriminate its numerosity (note that a test revealed that the pigeons had not relied on the number of feedback tones). Discrimination on the basis of the number of responses (pecking) might lead pigeons to perform in accord with the abstraction principle, since this is often the case when we count miscellaneous objects in everyday life.

Emmerton (1998) suggested that pigeons may scan visual arrays presented on two pecking keys in a simultaneous discrimination procedure, when they were required to choose the array of each pair that contained fewer dots. The pigeons were more accurate at choosing the smaller numerosity when the difference between the $\mathrm{S}+$ (smaller number array) and the $\mathrm{S}-$ (larger number array) was greater rather than smaller (distance effect). However, when the density, or interitem spacing, of the stimulus arrays was manipulated, discrimination accuracy was also influenced by variation in the density. Among four combinations of high density and low density for each numerosity pair (far +/near-, near+/near-, far +/far-, and near $+/$ far -$)$, the best discrimination accuracy was obtained when the smaller numerosity, S + array had widely spaced dots and the larger numerosity, $\mathrm{S}-$ array had closely spaced dots $($ far $+/$ near -$)$. The poorest performance was obtained with the opposite density combinations (near $+/$ far - ). These findings were opposite to those found in humans (e.g., Allik \& Tuulmets, 1991) and were explained by miscounts (missing one or more items), which were more likely to occur when the pigeons were scanning the widely rather than the closely spaced elements. Xia et al. (2001) discussed that their pigeons' having to peck each item of the numerosity stimuli might have enabled them to properly scan all the items in the array.

In the present study, we trained pigeons to peck each item in an array, with a numerical discrimination task similar to that used by Xia et al. (2001). Pecking each item, a white dot, turned each dot red and, consequently, marked the dot as counted (i.e., partitioning). The pigeons' peck- ing to each dot will be referred to as an indicating response in the following sections. In a series of experiments, we explored the following issues: the ordered representation of numerosities, the salience of the number of indicating responses as a cue for judgment of the absolute number of items, and the degree to which training can assist pigeons to discard nonnumerical cues.

In Experiment 1, pigeons were trained in a forced choice task with four alternatives to categorize stimulus arrays consisting of one, three, five, or eight white dots. They were then tested with novel numerosities $2,4,6$, and 7. If the pigeons formed an ordered representation, their responses for the familiar and novel numerosities would be distributed according to the order $1<2<3<$ $4<5<6<7<8$. Experiments 2,3 , and 4 examined the cues on which the pigeons based their choices. Davis and his colleagues claimed that animals rely on number only when there is no alternative solution for a task (Davis \& Memmott, 1982; Davis \& Pérusse, 1988; but see Cantlon \& Brannon, 2007; Meck \& Church, 1983). We examined control by possible nonnumerical cues that may have been available for the present task. These cues were the surface area, the time (how long the pigeons had spent pecking the numerosity stimulus), and the pecking rhythm. A single peck was required for an indicating response in Experiments 1 and 2, but the number of required pecks to each dot was varied in Experiment 4. In Experiment 3, the pigeons' pecks did not serve to partition the dots into those that had already been pecked and those that remained to be pecked (i.e., pecking the white dots did not change the color to red).

\section{EXPERIMENT 1}

We trained pigeons to choose one of the four comparison stimuli, depending on the absolute number of dots (one, three, five, or eight) in the stimulus arrays, which were displayed on a touch screen. The comparison stimuli appeared immediately after the "counting" phase, during which the pigeons were required to peck the white dots sequentially to change the color to red. We investigated whether the pigeons would learn the task, and then transfer to novel arrays consisting of two, four, six, or seven dots, in a manner consistent with ordinal information.

\section{Method}

\section{Subjects}

The subjects were 4 pigeons (Birds 1, 2, 3, and 4) maintained at $85 \%$ of their free-feeding body weight throughout the experiment, but with unlimited water and grit available in their individual home cages. They had previously performed tasks using the touch screen but did not have any prior experience with multiple-choice procedures or the numerical stimuli used in this study.

\section{Apparatus}

The experiment used four identical operant conditioning chambers that measured $35 \times 28 \times 35 \mathrm{~cm}$. The stimuli were presented on TFT color monitors (SHARP LL-T 1510R), which were visible through a viewing window (16 $\mathrm{cm}$ wide and $10 \mathrm{~cm}$ high) located in the middle of an aluminum panel in front of each chamber. The bottom edge of the viewing window was $20 \mathrm{~cm}$ above the cham- 
ber floor. The monitor was located $1.5 \mathrm{~cm}$ behind an infrared touch frame (Carroll Touch). Between the frame and the surface of the monitor was a thin Plexiglas sheet that shielded the monitor from direct contact. A food aperture $(7 \times 6 \mathrm{~cm})$ located in the middle of the front panel afforded the pigeons access to a solenoid-operated food tray containing a mixture of grains. A houselight $(3 \mathrm{~W})$ in the center of the ceiling dimly illuminated the chamber.

The chambers and the video monitors were located in a darkened testing room. The computer software for presentation of the stimuli, controlling the experimental events, and collecting the data was developed in Visual Basic 6.0 (Microsoft).

\section{Stimuli}

The training stimuli consisted of one, three, five, or eight dots approximately $0.5 \mathrm{~cm}$ (15 pixels) in diameter. At the start of the trials, all of the dots were illuminated in white on a black background. The test stimuli consisted of two, four, six, or seven dots. In each individual trial, the dots were randomly distributed in a $178 \times 178$ pixel (approximately $6.0 \times 6.0 \mathrm{~cm}$ ) central display area, with the constraint that any two dots were not closer than 45 pixels. The stimulus configuration was varied across trials and sessions to prevent the subjects from relying on a spatial configuration to discriminate the stimuli. The display area was framed with a white outline $(0.05-\mathrm{cm}$ width) that was presented continuously on the monitor throughout the sessions.

There were four circular areas (1.5-cm diameter), each located $1.5 \mathrm{~cm}$ from the corners of the central display area. These circular areas could be colored green, blue, purple, or yellow and served as the comparison stimuli.

\section{Procedure}

Pretraining. The pigeons did not have any prior experience with the dot patterns used as the numerical stimuli in this study. We therefore first trained the birds, by using conventional hand-shaping, to peck at a white dot in the display area. Only pecks on the dot, or in its vicinity (within a tolerance of a 5-mm-wide annular surround), were reinforced. We then trained the birds to peck the four comparison stimuli. After the pigeons reliably pecked the dot and the comparison stimuli, they were transferred to a training schedule. The training involved a discrete trial procedure with an intertrial interval of $5 \mathrm{sec}$.

Each trial began when the white $\operatorname{dot}(\mathrm{s})$ appeared on a black background in the display area. The number of dots gradually increased from one to three, then five, and then to eight, across sessions. A single peck to a white dot changed its color to red. Any further pecks on this dot had no consequences. Immediately after the color of all of the dots had been changed to red, the food hopper was presented. The duration of the reinforcement for each pigeon was constant within a session but varied across sessions, so that a pigeon's $85 \%$ body weight was maintained as closely as possible. In this training stage, the display of the red $\operatorname{dot}(\mathrm{s})$ continued during the reinforcement. A session consisted of 60 trials. The houselight was continuously on.

In the next training stage, the number of dots was varied from trial to trial. Immediately after the "counting" phase, during which the pigeons were required to peck all the dots to change the color from white to red, one comparison stimulus that was to be correct in the following discrimination training stages was presented. The green, purple, blue, and yellow comparison stimuli were correct for the numerosity stimuli $1,3,5$, and 8 , respectively, so that the assignment of the colors to the numerosities differed from the ordering implied by the colors (purple-blue-green-yellow). The location of the comparison stimuli (top left, top right, bottom left, and bottom right) was varied across pigeons but remained the same for each particular pigeon during all training and testing stages. A response to the comparison stimulus removed all the stimuli, and this was immediately followed by a food reward. This training stage lasted for two sessions, each of 60 trials.

Discrimination training. All of the comparison stimuli were presented following the "counting" phase. An incorrect choice pro- duced a blackout for $3 \mathrm{sec}$, and the same trial was repeated an unlimited number of times until the pigeon responded correctly. These correction trials were not taken into account for trial counts and performance scores.

Each of the four numerosity stimuli appeared on 3 trials in a randomized block of 12 trials. A session consisted of five blocks, and there were a total of 60 trials per session. The trials were randomized every day, with the restriction that the same numerosity could not occur more than three times in succession. Each bird was required to meet a criterion of $70 \%$ correct overall and $50 \%$ correct for each of the four numerosities in each of three consecutive sessions.

The number of training trials was then increased to 80 . A session then consisted of five randomized blocks of 16 trials. Each training block comprised 4 trials for each numerosity stimulus. The choice responses on 20 trials ( 4 numerosity stimuli $\times 5$ blocks) in a session were not followed by reinforcement or blackout but led directly to an intertrial interval. The correction procedure was not used during these 20 trials. Discrimination training was continued until the pigeons regained the performance criterion described above.

Testing. Each test session began with a block of 16 training trials ( 4 trials for each of the numerosities 1, 3, 5, and 8). These first 16 trials served as an assessment period to determine whether a subject's accuracy was high enough to permit testing. If, during the assessment period, the accuracy for one or more of the numerosities was less than $50 \%$, probe testing was not conducted in the remainder of the session. That session was then recorded as a training session. If a bird's performance level was $50 \%$ or better with each of the four numerosities, probe trials were inserted into the following four testing blocks of 16 trials. Each testing block comprised 3 training trials, each with the numerosity stimuli $1,3,5$, and 8 , and one probe trial each with the numerosity stimuli $2,4,6$, and 7 . The choices in the probe trials were not reinforced but led directly to an intertrial interval. Five test sessions were performed. Consequently, the total number of probe trials for each of the numerosity stimuli $(2,4,6$, and 7) was 20.

\section{Results}

\section{Discrimination Training}

Birds 1,2,3, and 4 attained $70 \%$ or better discrimination accuracy in 39, 44, 46, and 35 days, respectively. But later, many more sessions were required to achieve a $50 \%$, or better, accuracy with all of the numerosities for 3 consecutive sessions. This was due to the poor performance, although it was significantly better than chance, with the numerosity stimulus 5 . Birds 1, 2, 3, and 4 required 134, 163,145 , and 107 sessions, respectively, to meet this performance criterion. The mean correct performance accuracies on reinforced and nonreinforced trials in the last 5 sessions for the numerosity stimuli 1, 3, 5, and 8 were $80 \%$ (range, 72\%-98\%), 83\% (range, 75\%-92\%), 66\% (range, 58\%-77\%), and $84 \%$ (range, $72 \%-95 \%$ ), respectively. One-tailed binomial tests (chance performance $=$ $25 \%, N=100$ ) revealed that the correct choices were significantly higher than chance at the .01 level for all of the numerosities.

The panels on the left side in Figure 1 display the mean percentages of choices for the numerosity stimuli $1,3,5$, and 8 on the 20 nonreinforced trials in the last four sessions (i.e., a total of 20 trials for each of the four numerosities as for the test stimuli). The distribution of the choices indicates that when the birds erred, they tended to choose the comparison stimuli that were numerically close to the correct value. A chi-square test was used to examine the effect of numerosity on choice responses. We then calcu- 
Training
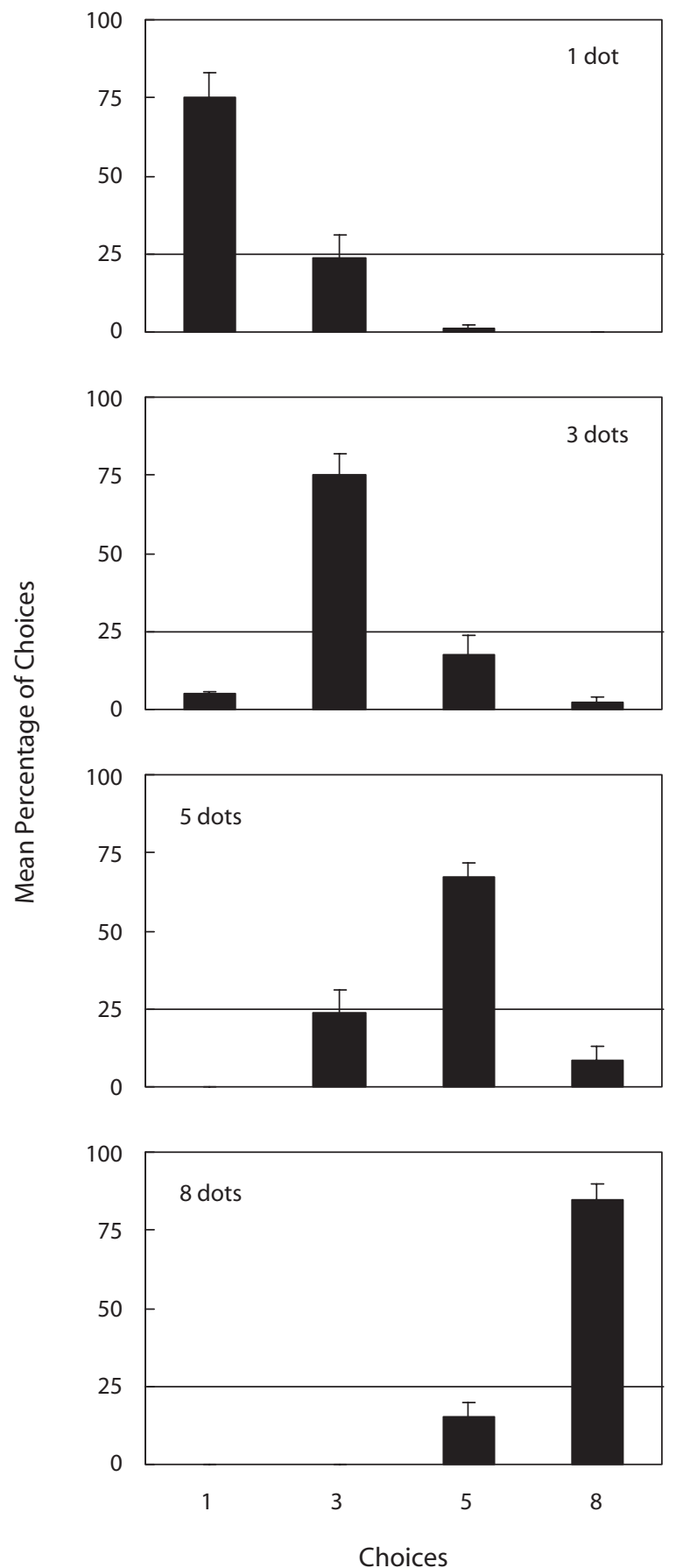

Test
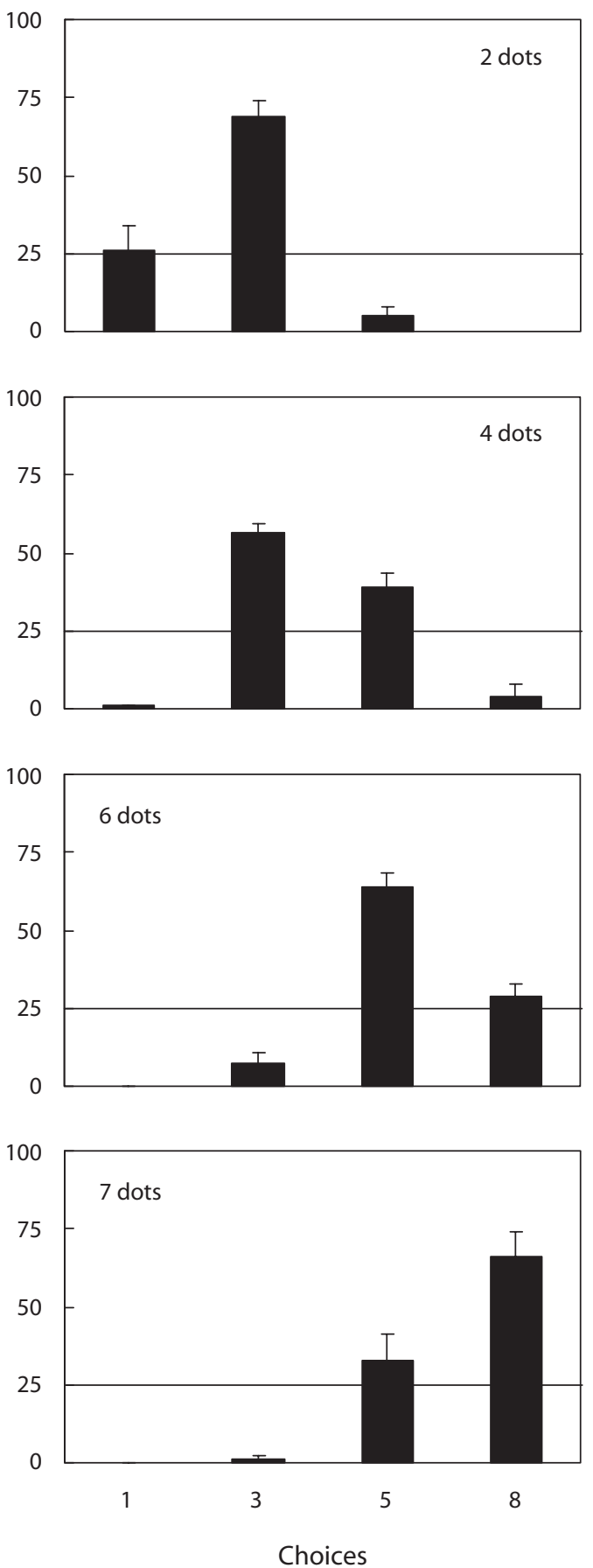

Figure 1. Left: Mean percentage of choices for the numerosity stimuli consisting of 1, 3, 5 , or 8 items, on the nonreinforced trials in the last four sessions of training (a total of 20 trials for each of the four numerosities). Right: Mean percentage of the choices for the novel numerosity stimuli consisting of 2, 4, 6, or 7 items, in the generalization testing of Experiment 1 (a total of 20 trials for each of the four numerosities). The error bars show standard errors.

lated Cramér's (1999) coefficient of association $V$ (between 0 and 1 ) as a measure of the strength of the relationship between the numerosities and choice responses. The effect $\left[\chi^{2}(9)=486.209, p<.001\right]$ was statistically significant, and the choice responses were highly dependent on the numerosities $(V=.712)$.

\section{Testing}

The panels on the right side in Figure 1 show the mean percentages of choice 1 , choice 3 , choice 5 , and choice 8 , for the novel numerosities $2,4,6$, and 7 . The pigeons consistently pecked numerically closer comparison stimuli more frequently than numerically distant comparison 
stimuli. One-tailed binomial tests (chance performance $=$ $25 \%, N=20$ ) revealed that the highest choice score was significantly greater than chance at the .01 level for all of the numerosities. A chi-square test revealed a significant effect of numerosity on choice responses $\left[\chi^{2}(9)=\right.$ $271.929, p<.001]$. The association strength $(V=.532)$ was smaller than that for the training stimuli described above, but choice responses were still highly related to the novel numerosities.

\section{Discussion}

The finding that the pigeons successfully learned to categorize the numerical arrays confirms the previous finding of Xia et al. (2001) that pigeons can discriminate absolute numbers at least within a small number range (1-5 in Xia et al. [2001] and 1-8 in the present study). An important finding of the present study is that pigeons can serially order novel numerosities on the basis of their previous training. With the numerosities used for training and testing, the highest reported score occurred at the following: choice 1 for the numerosity stimulus 1 ; choice 3 for the numerosity stimuli 2, 3, and 4; choice 5 for the numerosity stimuli 5 and 6 ; and choice 8 for the numerosity stimuli 7 and 8 . A close inspection of the gradients shown in Figure 1 suggests that the pigeons judged the numerosities to be in the order $1<2<3<4<5<6<7<8$. These findings clearly indicated that the pigeons were not simply memorizing which comparison stimulus was correct for each numerosity stimulus used for training. Rather, the pigeons were basing their choices on an ordinal representation of the numerosities.

\section{EXPERIMENT 2}

In Experiment 1, the pigeons were explicitly trained to emit indicating responses to the items in a display before they chose a comparison stimulus. However, the number of indicating responses was not the only dimension along which pigeons could order the stimuli. Because all the dots were the same size within and also across arrays, one possible nonnumerical cue was the cumulative surface area of the red dots presented at the time of choice. The dots were randomly located in the display area, and therefore, density of the dots of the same numerosity varied across trials; the dots were close together on some trials and more widely spaced on other trials. Although covariation of number and overall density could occur on average over trials, it seems unlikely that the pigeons used the density as a basis for judgment in this task. Also, the finding of Emmerton (1998), described earlier, suggests that interdot spacing might not have affected the pigeons' discrimination accuracy in the present study. Pigeons' discrimination accuracy with density-controlled stimuli in the study of Emmerton (1998) was controlled primarily by the size of numerosity difference. The effect of density was attributable to miscounts of widely spaced dots, which could be eliminated by the indicating response in the present study.

Experiment 2 controlled the surface area of red dots by removing some of the dots from the screen when they were pecked by the pigeons. For example, two dots in a five-dot array were removed, and there were only three red dots at the time of choice. A question of interest was whether the pigeons would choose the comparison stimulus corresponding to the numerosity 3 or 5 . In this way, in Experiment 2, we examined whether the pigeons would respond according to the surface area existing at the time of choice or to the number of indicating responses (i.e., the number of white dots).

\section{Method}

Subjects, Apparatus, and Stimuli

The subjects, apparatus, and stimuli were the same as those in Experiment 1.

\section{Procedure}

All aspects of the general procedure not specifically mentioned below were the same as those in Experiment 1.

Approximately 3 months after Experiment 1 was completed, the same pigeons were retrained with the $1,3,5$, and 8 numerosity stimuli. This retraining continued for a minimum of 20 sessions and until the performance criterion was regained. They then proceeded to a series of sessions involving pretest, training to eliminate the surface cue, and posttest. The pretest and posttest evaluated the extent to which the pigeons' discrimination of numerosity stimuli could be related to the number of indicating responses (i.e., the number of white dots).

Pretest. Each test session consisted of an assessment period (16 trials), followed by 46 standard training trials and 18 randomly located test trials. The test trials were conducted in the same way as the standard training trials, except that a given number of dots were removed from the screen after they had been pecked. When the pigeons were required to choose a comparison stimulus, there were only one, three, and five red dots for the numerosity stimulus 8 (white 8/red 1, white 8/red 3, and white 8/red 5); only one and three red dots for the numerosity stimulus 5 (white $5 /$ red 1 , white $5 /$ red 3 ); and only one red dot for the numerosity stimulus 3 (white 3/red 1). Each of these six types of trial occurred three times in a session, and the dots that were to be removed were randomly determined for every individual trial. In these 18 test trials, the choice responses were followed by nondifferential food reinforcement (i.e., food was presented after all choices). The remaining 46 trials were standard training trials consisting of 16 trials of eight dots, 13 trials of five dots, 10 trials of three dots, and 7 trials of one dot. Consequently, the total number of training and test trials with the given number of red dots was equal to 16 . Each pigeon received six test sessions.

Training to eliminate the surface cue. For this part of the experiment, each of the numerosity stimuli $1,3,5$, and 8 appeared 20 times in a session (five randomized blocks of 16 trials). In 36 randomly designated trials, a given number of dots were removed from the screen in the same manner as in the pretest trials. Each of the six trial types occurred 6 times in a session. The choices that agreed with the number of indicating responses (i.e., the number of white dots) led to food presentation. Incorrect choices, including those that agreed with the number of red dots, led to blackout, followed by a correction procedure. Each pigeon received 45 sessions.

Posttest. After completing the training to eliminate the surface cue, the pigeons received posttest sessions, which were exactly the same as those previously described for the pretest sessions. Nondifferential reinforcement of choice responses that had been removed for the training to eliminate the surface cue was thus reinstituted on test trials (i.e., food was presented after all choices, as it was in the pretest sessions).

\section{Results and Discussion}

\section{Pretest}

Figure 2 shows the mean distribution of choices for two variables: the number of white dots (white 1, white 3 , 

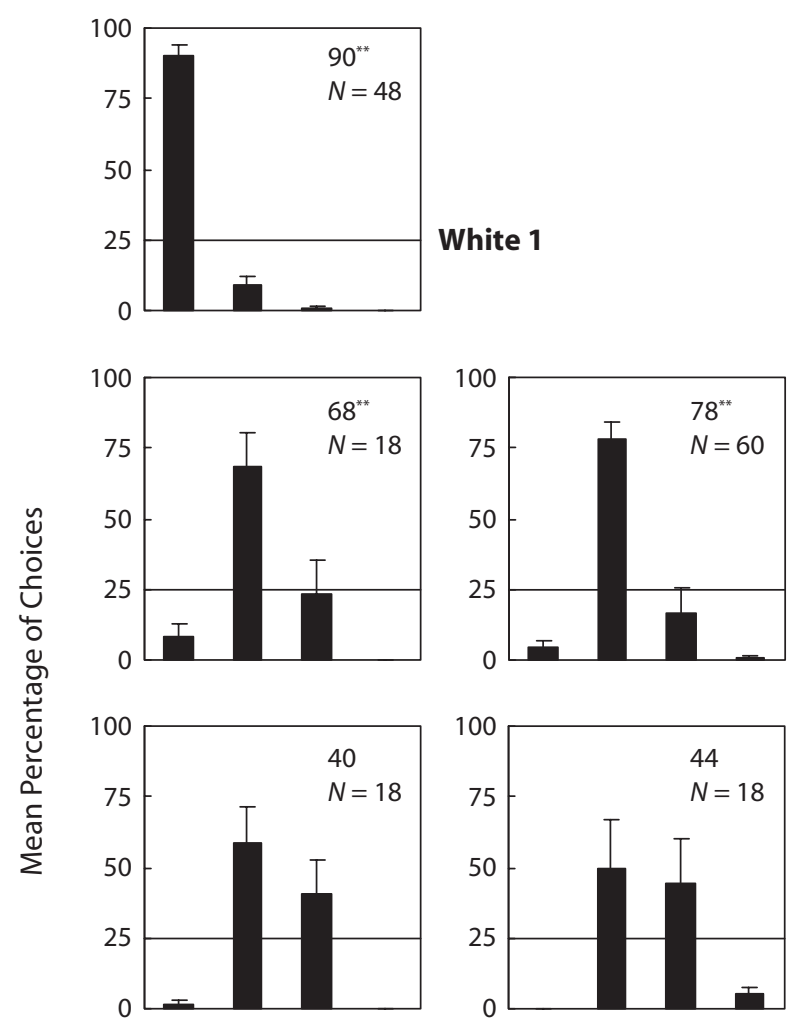

White 3

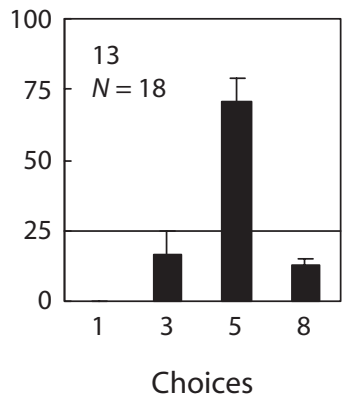

Red 1
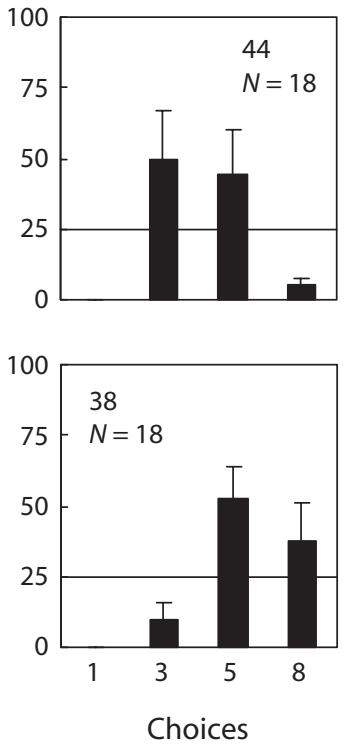

Red 3

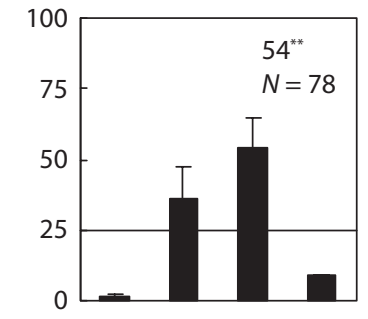

White 5

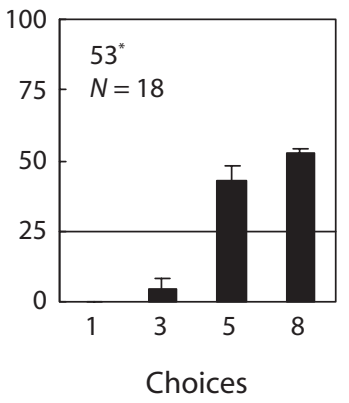

Red 5

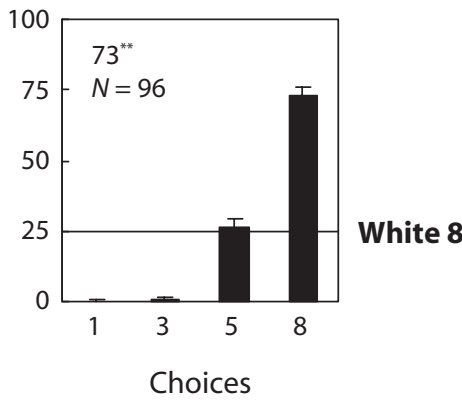

Red 8

Figure 2. Mean percentages of choices represented along two variables in pretest sessions of Experiment 2: the number of white dots (white 1, white 3, white 5, and white 8) and the number of red dots presented at the time of choice (red 1, red 3, red 5, and red 8). The number in each panel is the percentage of choices that are scored as correct according to the number of white dots or the number of indicating responses. The error bars show standard errors. Chance performance is $25 \%$ correct. ${ }^{*} p<.05$, one-tailed binomial test. ${ }^{* *} p<.01$, one-tailed binomial test.

white 5 , and white 8 ) and the number of red dots that remained until the pigeons chose a comparison stimulus (red 1 , red 3 , red 5, and red 8 ). The number in each panel is the percentage of choices that were correct according to the number of white dots. A comparison of the panels by rows suggests that the correct choices tended to decrease as the number of red dots decreased. Similarly, a comparison of the panels by columns suggests that the correct choices tended to decrease as the number of white dots increased. These findings jointly suggested that the correct choices decreased as the difference in the number of white and red dots increased. In addition, the distribution of choices indicated that the pigeons tended to underestimate when the number of red dots decreased.
The columns on the left side of Table 1 show the results of chi-square tests and Cramér's (1999) $V$ values, which were separately calculated for the following relationships: the number of red dots and choice responses for the stimuli involving three, five, or eight white dots (white 3, white 5, and white 8 in the table); and the number of white dots and choice responses for the stimuli involving one, three, or five red dots (red 1, red 3, and red 5 in the table). All the effects were significant, except that the number of red dots for the numerosity stimulus 3 (white 3 ) was not significantly related to the choice responses. However, Cramér's coefficient of association was larger for the effect of the number of white dots (range, .473-.589) than for the number of red dots (range, .116-.267), suggesting that the 
Table 1

Results of Experiment 2 for Chi-Square Tests and Cramér's (1999) $V$ Values for the Relationship Between the Number of Red Dots and Choice Responses and Between the Number of White Dots and Choice Responses

\begin{tabular}{|c|c|c|c|c|}
\hline \multirow[b]{2}{*}{ Related Variable } & \multicolumn{2}{|l|}{ Pretest } & \multicolumn{2}{|l|}{ Posttest } \\
\hline & Chi-Square Test & $\begin{array}{c}\text { Cramér's } \\
\text { Coefficient } V\end{array}$ & Chi-Square Test & $\begin{array}{c}\text { Cramér's } \\
\text { Coefficient } V\end{array}$ \\
\hline \multicolumn{5}{|l|}{ Number of Red Dots } \\
\hline White 3 & $\chi^{2}(3)=4.20, p=.240$ & .116 & $\chi^{2}(3)=0.38, p=.946$ & .035 \\
\hline White 5 & $\chi^{2}(6)=18.92, p=.004^{*}$ & .144 & $\chi^{2}(6)=4.36, p=.629$ & .069 \\
\hline White 8 & $\chi^{2}(9)=128.11, p<.001^{* *}$ & .267 & $\chi^{2}(9)=10.50, p=.312$ & .076 \\
\hline \multicolumn{5}{|c|}{ Number of White Dots } \\
\hline Red 1 & $\chi^{2}(9)=399.56, p<.001^{* *}$ & .589 & $\chi^{2}(9)=634.55, p<.001^{* *}$ & .742 \\
\hline Red 3 & $\chi^{2}(6)=171.58, p<.001^{* *}$ & .473 & $\chi^{2}(6)=259.83, p<.001^{* *}$ & .582 \\
\hline Red 5 & $\chi^{2}(3)=89.26, p<.001^{* *}$ & .482 & $\chi^{2}(3)=118.77, p<.001^{* *}$ & .556 \\
\hline
\end{tabular}

pigeons' choice responses were more strongly related to the number of white dots than to the number of red dots.

\section{Posttest}

Figure 3 shows the results from the posttest. The pigeons most frequently chose the correct comparison stimulus according to the number of white dots, and the percentage of correct choices was significantly higher than chance for all of the stimuli. A comparison of the panels in rows suggests that there was not a notable difference in the choice response depending on the number of red dots. These findings were confirmed by chi-square tests and Cramér's (1999) coefficients of association shown in the columns on the right side of Table 1 . We may therefore now conclude that the pigeons' choice responses were related solely to the number of white dots that naturally covaried with the number of indicating responses.

\section{Comparison of Correct Performance Between the Tests}

A two-way ANOVA, with test (pretest vs. posttest) and test stimulus (white $8 /$ red 1 vs. white $8 /$ red 3 vs. white $8 /$ red 5 vs. white $5 /$ red 1 vs. white $5 /$ red 3 vs. white $3 /$ red 1 ) as within-subjects variables, was conducted on choice performances scored as correct according to the number of white dots. The main effect of test was significant $[F(1,3)=$ $40.909, p=.008]$. Because the interaction was significant $[F(5,15)=4.526, p=.01]$, we analyzed the simple main effects of the variables. The simple main effects of test were significant for white $8 /$ red $1[F(1,18)=38.118$, $p<.001]$, white $8 /$ red $3[F(1,18)=14.890, p=.001]$, and white $8 /$ red $5[F(1,18)=5.360, p=.033]$. The effect was marginally significant for white $5 /$ red $1[F(1,18)=$ $3.243, p=.089]$. The findings reflected that the decreased number of red dots increased underestimation for the large numbers and this detrimental effect was removed by the training to eliminate the surface cue. The simple main effects of test stimulus were significant in both the pretest $[F(5,30)=5.772, p<.001]$ and the posttest $[F(5,30)=$ $2.640, p=.043]$. A remarkable finding was that the pigeons performed poorly, although significantly better than chance, with the numerosity stimulus 5 . This finding will be considered in the General Discussion section.

We controlled the number of red dots in order to examine the effect of surface area. It has often been argued that animals rely on number only when there is no alternative solution available for the task at hand (Davis \& Memmott, 1982; Davis \& Pérusse, 1988). In contrast to this last-resort hypothesis, the pigeons in the pretest sessions relied more on the number of white dots, or the number of indicating responses, than on surface area or any other nonnumerical cues (e.g., brightness of the display area at the time of choice) that covaried with the number of red dots. A finding contrary to the last-resort hypothesis was recently reported with rhesus monkeys in the study of Cantlon and Brannon (2007), using a matching task with more than one correct answer (a numerical match based on the number of items and a nonnumerical match based on color, surface area, or shape).

However, we still cannot exclude the possibility that the pigeons used surface area or brightness of the display area at the time of initial presentation (i.e., before the time of choice) as the basis for responding to the comparison stimuli. That is, the pigeons could have relied on the nonnumerical cues that covaried with the number of white dots before pecking was initiated.

\section{EXPERIMENT 3}

This experiment was designed to examine the role of the nonnumerical cues that covaried with the number of white dots, which could have influenced the performance reported in Experiments 1 and 2. An additional motivation for Experiment 3 was to examine the possibility that the pigeons were relying on the number of white dots per se, perceiving the array holistically, with all items being processed or counted in parallel.

\section{Method}

\section{Subjects, Apparatus, and Stimuli}

The subjects, apparatus, and stimuli were the same as those in Experiments 1 and 2 .

\section{Procedure}

Each session consisted of an assessment period (16 trials), followed by 48 standard training trials ( 4 numerosity stimuli $\times 12$ trials) and 16 randomly located test trials ( 4 numerosity stimuli $\times 4$ trials). In the test trials, the comparison stimuli were presented at the same time as an array of white dots. Pecks to the items were ineffective in changing the color of the white dots to red, and all of the white dots were present until a comparison stimulus was chosen. The choice responses were nondifferentially reinforced (i.e., food was presented 


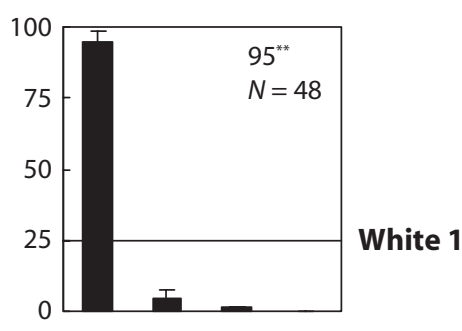

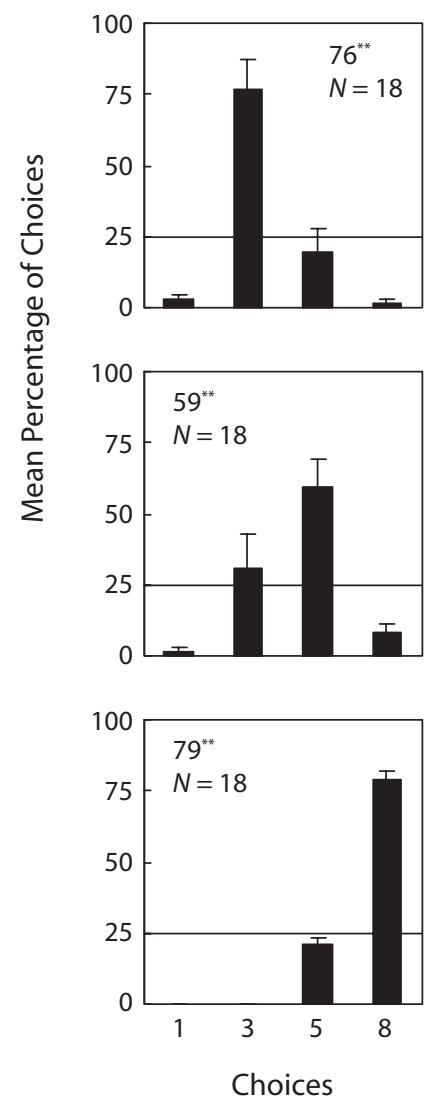

Red 1

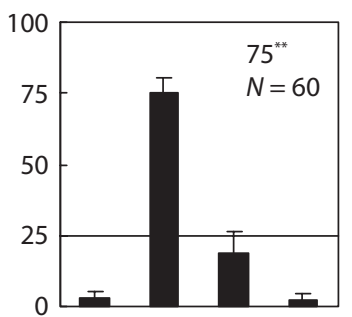

White 3
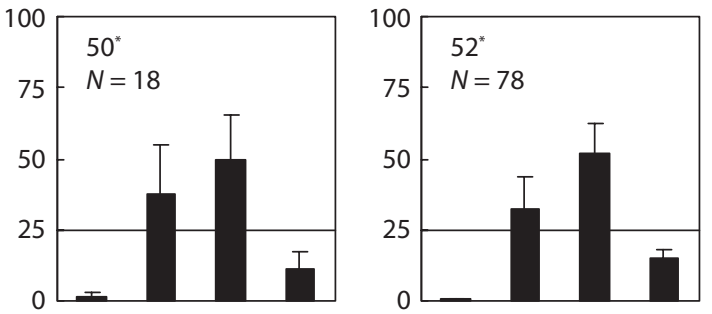

White 5

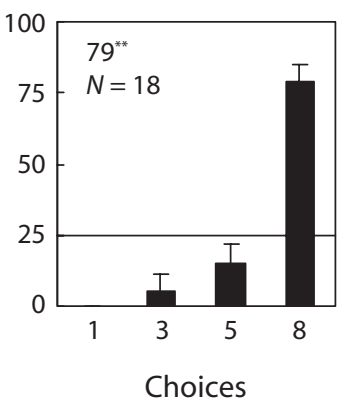

Red 3

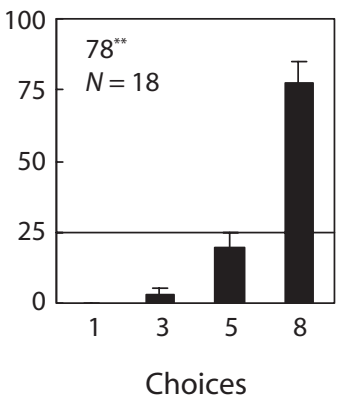

Red 5

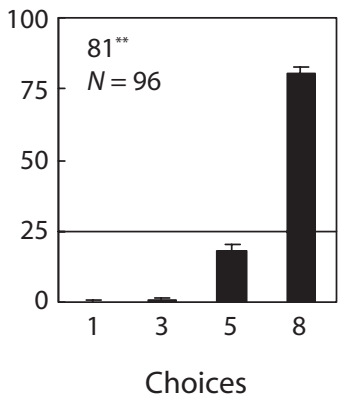

Red 8

Figure 3. Mean percentages of choices represented along two variables in posttest sessions of Experiment 2: the number of white dots (white 1, white 3, white 5, and white 8) and the number of red dots presented at the time of choice (red 1, red 3, red 5, and red 8). The number in each panel is the percentage of choices that were correct, according to the number of white dots or the number of indicating responses. The error bars show standard errors. Chance performance is $25 \%$ correct. ${ }^{*} p<.05$, one-tailed binomial test. ${ }^{* *} p<.01$, one-tailed binomial test.

after all choices). Ten test sessions were performed. Other procedural details were the same as those in the preceding experiments.

We were concerned that the testing procedure would possibly affect the pigeons' baseline performance. Therefore, Experiment 3 was actually carried out at the very end of the series of experiments in the present study (i.e., after Experiment 4).

\section{Results and Discussion}

Figure 4 shows the mean percentages of choice 1 , choice 3 , choice 5 , and choice 8 , for the numerosity stimuli $1,3,5$, and 8 , in the test trials. The pigeons primarily responded to the choice 1 comparison stimulus, with no or few responses to the other comparison stimuli. The mean percentages of choice 1 responses for the numerosity stimuli 1, 3, 5, and 8 were $96 \%$ (range, $88 \%-100 \%$ ), $96 \%$ (range, 85\%-100\%), 98\% (range, 93\%-100\%), and 98\% (range, 90\%-100\%), respectively. Informal observations revealed that the pigeons repeatedly pecked at a single dot when the dot failed to change color. They then often accessed one or more other dots but repeatedly pecked one before choosing a comparison stimulus. Pausing, flapping, walking, and other activities were often observed before pecking to the other dot. A plausible explanation was that they had focused on just one item in the array before choosing a comparison stimulus (an account in line with the serial processing proposed by Emmerton, 1998). Another possibility was that, because the pigeons had shown the highest accuracy with the numerosity stimulus 1 in the preceding experiments (see Figures 2, 3, 5, and 6), their 

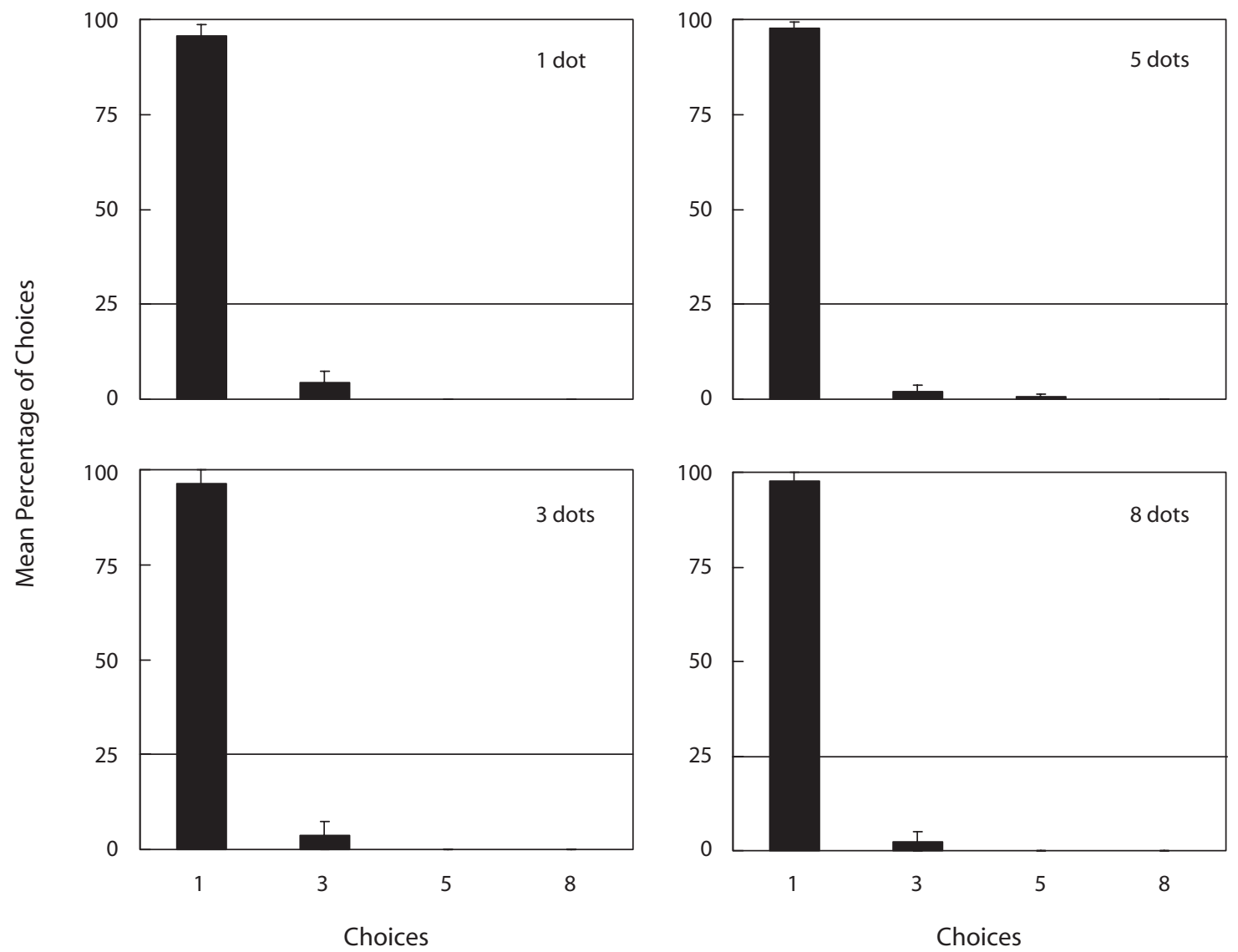

Figure 4. Mean percentages of choices on test trials in Experiment 3, where pecks to the items were ineffective in changing the color of the white dots to red. The error bars show standard errors.

response to the choice 1 comparison stimulus was more likely to be rewarded than responses to any other comparison stimuli. It may be also argued that zero (there was not a single dot that had changed its color from white to red) is more similar to 1 than to any other numbers. It is not clear why the pigeons produced almost exclusively choice 1 responses, but it is clear that they were not relying on the number of white dots that could be processed or counted in parallel or on the related nonnumerical cues (surface area and brightness of the initial display).

\section{EXPERIMENT 4}

Taken together, the results of Experiments 2 and 3 indicated that the number of indicating responses was critical for the pigeons to categorize the numerical arrays. However, because a single peck was required for every item, the number of indicating responses covaried with the time spent for pecking. Experiment 4 controlled the total number of pecks required during the "counting" phase. For example, two dots in a three-dot array each required two pecks, and the other one required a single peck to change the color to red (thus, the total number of pecks was five). A question of interest was whether the pigeons would choose the comparison stimulus corresponding to the numerosity 3 or 5 . In this way, Experiment 4 examined whether the pigeons' discrimination could be related to the number of indicating responses and not just to the time or the total number of pecks.

\section{Method}

Subjects, Apparatus, and Stimuli

The subjects, apparatus, and stimuli were the same as those in Experiments 1, 2, and 3.

\section{Procedure}

The pigeons were retrained in the standard discrimination procedure for a minimum of 15 sessions with the numerosity stimuli 1 , 3,5 , and 8 , until the performance criterion (described earlier) was regained. They then proceeded to pretest, training to eliminate the temporal cue, and then posttest. The pretest and posttest evaluated the extent to which the pigeons' discrimination of the numerosity stimuli could be related to the number of indicating responses.

Pretest. The same procedure as the pretest in Experiment 2 was used, except for the following details of the test trials.

The total number of pecks required during the "counting" phase varied systematically. The total numbers of pecks were three, five, and eight for the numerosity stimulus 1 , five $(1+1+3$ or $1+$ $2+2)$ and eight $(3+3+2)$ for the numerosity stimulus 3 , and eight $(3+2+1+1+1$ or $2+2+2+1+1)$ for the numerosity stimulus 5 . In the $1+1+3$ trials, for example, two of the three dots required a single peck, and the other dot required three pecks to change the color to red, with the assignment of the required number of pecks to the three dots randomly determined for every individual trial. Each of these six trial types occurred three times in a session. 
The $1+1+3$ and $1+2+2$ trials for the numerosity stimulus 3 , and the $3+2+1+1+1$ and $2+2+2+1+1$ trials for the numerosity stimulus 5 occurred equally often (three times each) in two successive sessions. The remaining trials were standard training trials. These training trials involved 7 eight-dot, 10 five-dot, 13 three-dot, and 16 one-dot trials (i.e., the total number of training and test trials with the given number of required pecks was 16). Each pigeon received six test sessions.

Training to eliminate the temporal cue. In a manner similar to that for the training to eliminate the surface cue in Experiment 2, each of the numerosity stimuli $1,3,5$, and 8 appeared 20 times in a session (five randomized blocks of 16 trials). In 36 randomly designated trials, the total number of required pecks varied in the same manner as in the pretest test trials. Each of the six trial types occurred 6 times in a session. The choices that agreed with the number of indicating responses led to food presentation. Incorrect choices, including those that agreed with the total numbers of required pecks, led to blackout, followed by a correction procedure. Each pigeon received 45 sessions.

Posttest. After completing the training to eliminate the temporal cue, the pigeons received posttest sessions that were exactly the same as those previously described for the pretest sessions.

\section{Results and Discussion}

\section{Pretest}

Figure 5 shows the mean distribution of the choices for two variables: the number of dots ( 1 dot, 3 dots, 5 dots, and 8 dots) or the number of indicating responses, and the total number of peck responses (response 1, response 3, response 5, and response 8). It was found in Experiment 3 that the pigeons were relying on the number of indicating responses, rather than on the number of dots per se. However,

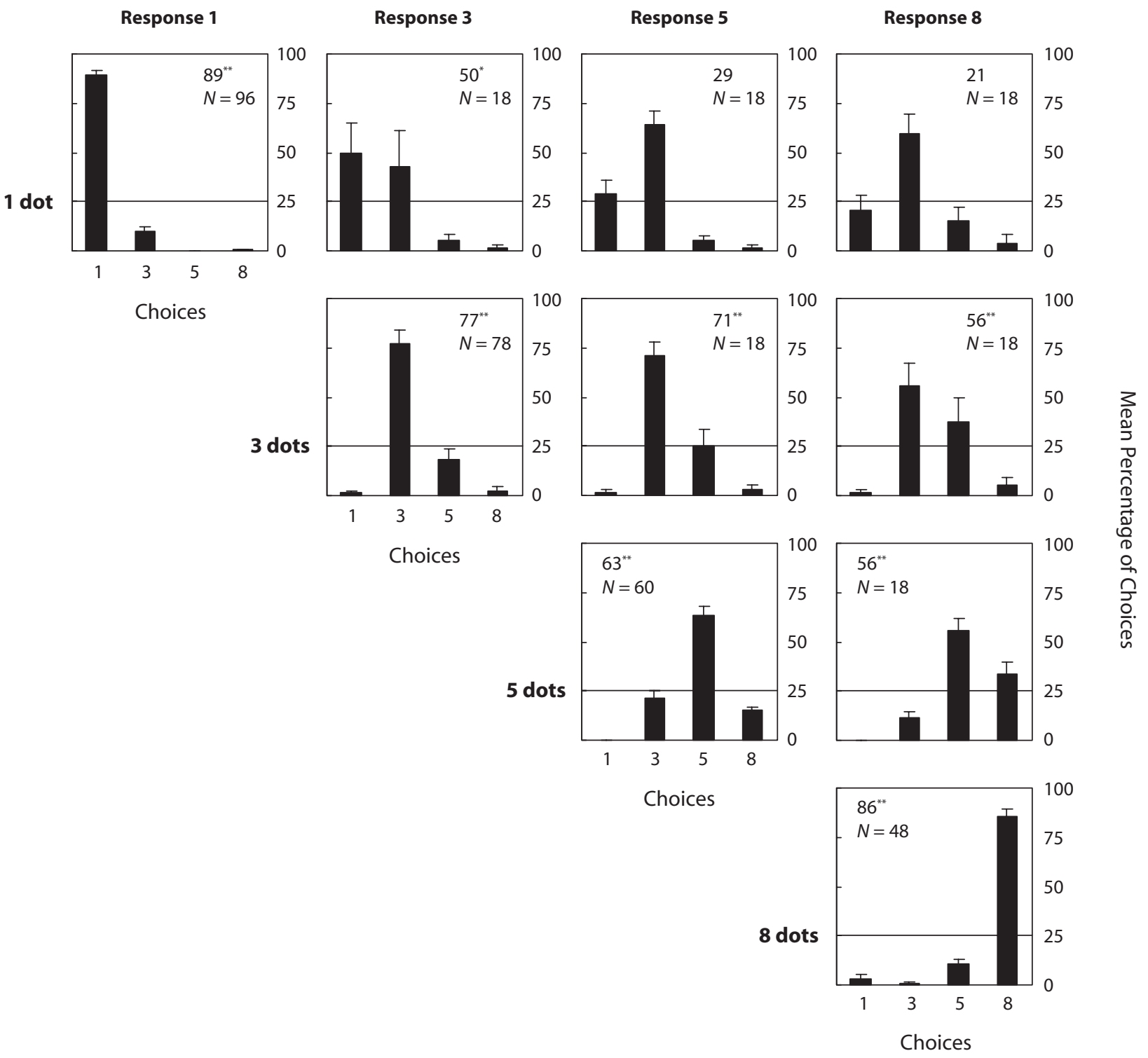

Figure 5. Mean percentages of choices represented along two variables in pretest sessions of Experiment 4: the number of items (1 dot, 3 dots, 5 dots, and 8 dots) and the total number of peck responses (response 1, response 3, response 5, and response 8). The number in each panel is the percentage of choices that were correct according to the number of items or the number of indicating responses. The error bars show standard errors. ${ }^{*} p<.05$, one-tailed binomial test. ${ }^{* *} p<.01$, one-tailed binomial test. 
in the following sections, the former variable will be referred to as the number of dots, as in Experiments 1 and 2.

The number in each panel is the percentage of the choices that were scored as correct according to the number of dots. A comparison across the panels revealed that the correct choices decreased as the difference between the number of dots (i.e., the number of counting responses) and the total number of required pecks increased. In addition, the distribution of the choices indicated that the pigeons tended to overestimate when the number of required pecks increased.

The columns on the left side in Table 2 show the results of chi-square tests and Cramér's (1999) $V$ values, which were separately calculated for the following relationships: the total number of pecks and the choice responses for the stimuli involving one, three, or five dots ( 1 dot, 3 dots, and 5 dots in the table); and the number of dots and the choice responses for the stimuli required three, five, or eight pecks (response 3 , response 5 , and response 8 in the table). All of the effects were significant. However, Cramér's coefficient of association was larger for the effect of the number of dots (range, .507-.613) than for the total number of required pecks (range, .129-.363). This result suggested that the pigeons' choice responses were related more to the number of dots (i.e., the number of indicating responses) than to the total number of required pecks.

\section{Posttest}

Figure 6 shows the results from the posttest. The performance accuracy with the numerosity stimuli 1 and 3 still tended to decrease as the total number of required pecks
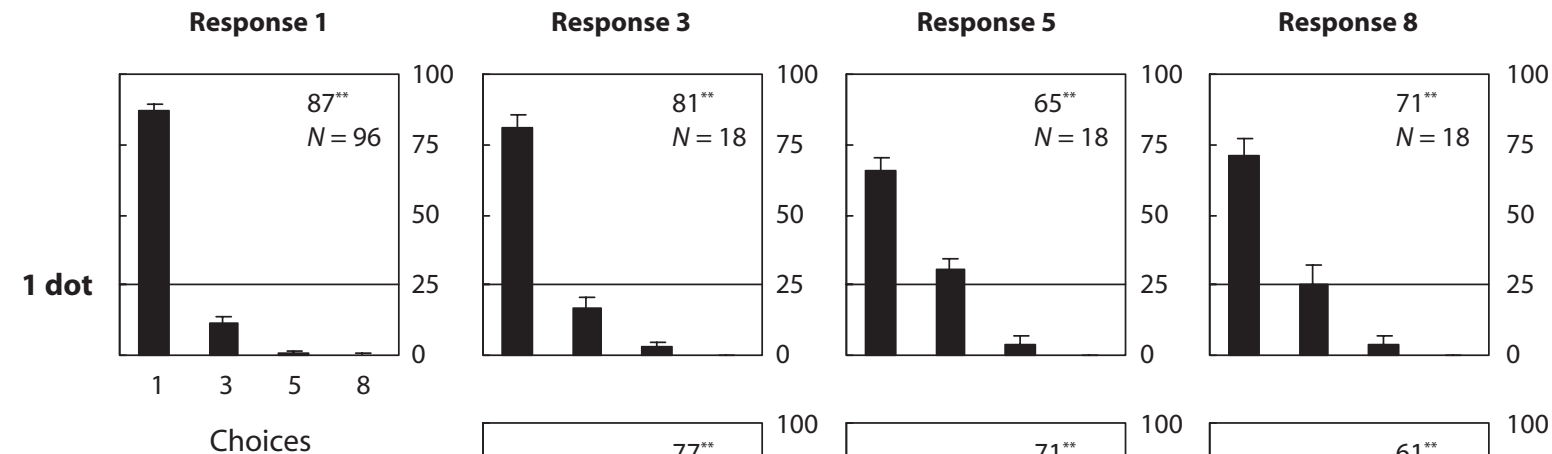

Choices
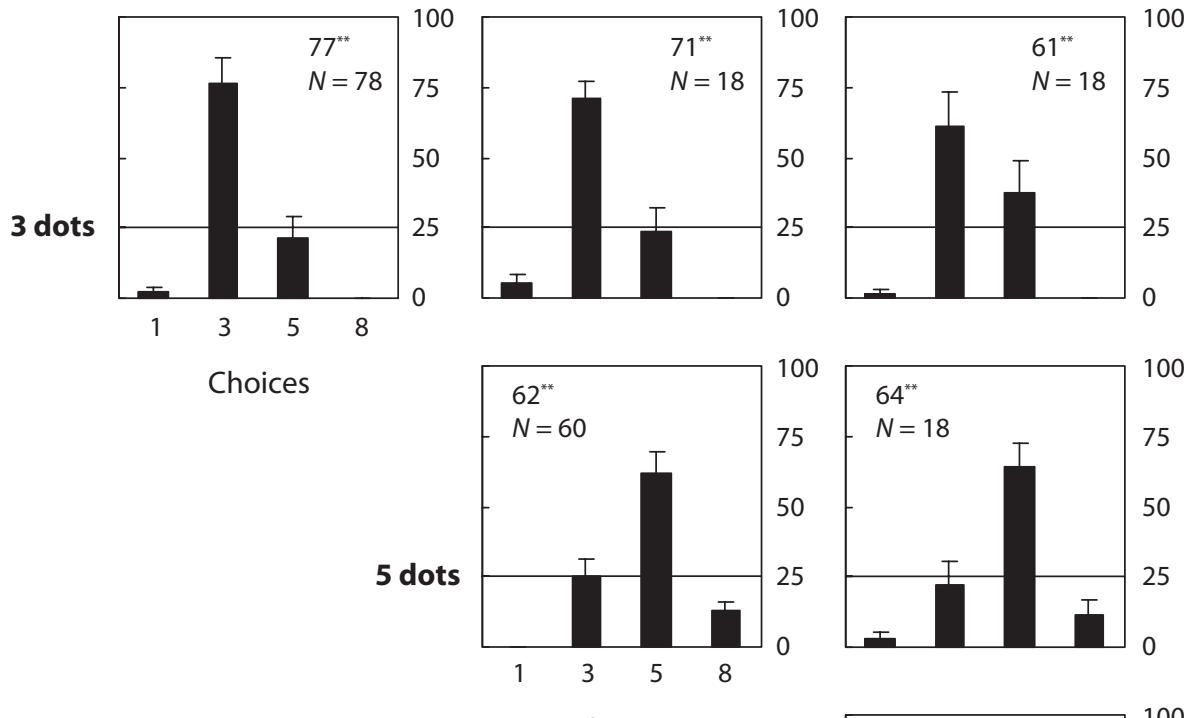

Choices

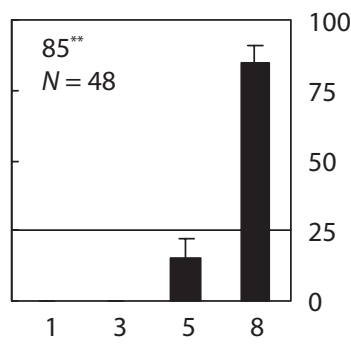

Choices

Figure 6. Mean percentages of choices represented along two variables in posttest sessions of Experiment 4: the number of items ( 1 dot, 3 dots, 5 dots, and 8 dots) and the total number of peck responses (response 1, response 3, response 5, and response 8). The number in each panel is the percentage of choices that were correct according to the number of items or the number of indicating responses. The error bars show standard errors. ${ }^{* *} p<.01$, one-tailed binomial test. 
Iable 2

Results of Experiment 4 for Chi-Square Tests and Cramér's (1999) $V$ Values for the Relationship Between the Total Number of Required Pecks and Choice Responses and Between the Number of Dots and Choice Responses

\begin{tabular}{|c|c|c|c|c|}
\hline \multirow[b]{2}{*}{ Related Variable } & \multicolumn{2}{|l|}{ Pretest } & \multicolumn{2}{|l|}{ Posttest } \\
\hline & Chi-Square Test & $\begin{array}{c}\text { Cramér's } \\
\text { Coefficient } V\end{array}$ & Chi-Square Test & $\begin{array}{c}\text { Cramér's } \\
\text { Coefficient } V\end{array}$ \\
\hline \multicolumn{5}{|l|}{ Number of Pecks } \\
\hline $1 \mathrm{dot}$ & $\chi^{2}(9)=236.57, p<.001^{* *}$ & .363 & $\chi^{2}(9)=29.78, p<.001^{* *}$ & .129 \\
\hline 3 dots & $\chi^{2}(6)=15.07, p=.020^{+}$ & .129 & $\chi^{2}\left(4^{\#}\right)=11.41, p=.022^{+}$ & .112 \\
\hline 5 dots & $\chi^{2}\left(2^{\#}\right)=13.43, p=.001^{*}$ & .208 & $\chi^{2}(3)=7.08, p=.069$ & .151 \\
\hline \multicolumn{5}{|l|}{ Number of Dots } \\
\hline Response 3 & $\chi^{2}(3)=144.49, p<.001^{* *}$ & .613 & $\chi^{2}\left(2^{\#}\right)=255.25, p<.001^{* *}$ & .815 \\
\hline Response 5 & $\chi^{2}(6)=197.75, p<.001^{* *}$ & .507 & $\chi^{2}(6)=283.57, p<.001^{* *}$ & .608 \\
\hline Response 8 & $\chi^{2}(9)=312.77, p<.001^{* *}$ & .521 & $\chi^{2}(9)=519.33, p<.001^{* *}$ & .671 \\
\hline
\end{tabular}
(two-tailed)

increased. This finding was confirmed by the results of the chi-square tests in the columns on the right side of Table 2. However, Cramér's (1999) $V$ values for the effect of the number of pecks decreased, and those for the effect of the number of dots increased, as compared with the corresponding values in the pretest.

\section{Comparison of Correct Performance Between the Tests}

A two-way ANOVA, with test (pretest vs. posttest) and test stimulus ( $1 \mathrm{dot} /$ response 3 vs. 1 dot/response 5 vs. $1 \mathrm{dot} /$ response 8 vs. 3 dots/response 5 vs. 3 dots/response 8 vs. 5 dots/response 8 ) as within-subjects variables, was conducted on choice performances scored as correct according to the number of dots. The main effect of test was significant $[F(1,3)=154.116, p=.001]$. Because the interaction was significant $[F(5,15)=12.558, p<.001]$, we analyzed the simple main effects of the variables. The simple main effects of the test were significant for $1 \mathrm{dot} /$ response 3 $[F(1,18)=31.565, p<.001], 1 \mathrm{dot} / \mathrm{response} 5[F(1,18)=$ $44.087, p<.001]$, and $1 \mathrm{dot} /$ response $8[F(1,18)=5.360$, $p=.033]$. The findings reflected the fact that the increased number of pecks increased overestimation for the numerosity stimulus 1 and this detrimental effect was removed by the training to eliminate the temporal cue. The simple main effects of stimulus type were significant in both the pretest $[F(5,30)=21.708, p<.001]$ and posttest $[F(5,30)=$ $3.045, p=.024]$. Again, the pigeons performed poorly with the numerosity stimulus 5 .

We controlled the total number of pecks in order to examine the usage of the temporal cue by pigeons. Roberts and Boisvert (1998) claimed that time is a more salient or primary dimension for animals than is number (see also Breukelaar \& Dalrymple-Alford, 1998). But we observed that the number of dots (i.e., the number of indicating responses) controlled the choice of the pigeons more than did the temporal cue or any other event, including the pecking rhythm, which covaried with the total number of pecks.

\section{GENERAL DISCUSSION}

These experiments were initiated by an interest in whether pigeons could utilize the number of indicating responses to categorize numerical arrays in accord with the absolute number of items. As we have described earlier with respect to partitioning (i.e., the distinction between items to be counted and those already counted), the indicating response (first used by Xia et al., 2001) would assist the pigeons in accessing each item only once and in sequentially scanning every item in a display. This was confirmed by informal observations of the pigeons engaging in the present task. The pigeons, in fact, categorized the numerical arrays to a high level of accuracy, and their performance was severely disrupted when their pecks did not serve to partition the dots (Experiment 3). However, because we did not have a control group that was trained to discriminate the absolute numbers of items without making an indicating response, it remains to be seen whether indicating response is truly necessary for pigeons to learn the numerical discrimination task.

The pigeons persistently showed a strong tendency to perform less accurately with the numerosity stimulus 5 than with any other numerosity stimuli. The endpoints of the scale (i.e., 1 and 8) were less likely to be confused with their adjacent numerosity than were the intermediates (i.e., 3 and 5). The pigeons actually performed accurately with the numerosity stimuli 1 and 8 throughout the experiments. One exception was that a considerable number of choice 3 errors occurred with the numerosity stimulus 1 on the nonreinforced trials in Experiment 1 (the top-left panel in Figure 1). Note also that there were no, or few, choice 1 errors for the arrays containing three or more dots (see the figures in Experiments 1, 2, and 4). This might have resulted in the accurate performance with the numerosity stimulus 3 that was comparable to performance with the two extreme array sizes. In contrast, the pigeons made a considerable number of choice 3 and choice 8 errors for the numerosity stimulus 5 . They were more strongly inclined to underestimate and respond with choice 3 than to overestimate and respond with choice 8 . This asymmetrical tendency could be explained by the loss of indicating responses in memory, although the validity of this explanation should await systematic investigation in the future.

The cardinal principle of counting states that the last tag represents the numerosity of the set. Despite the find- 
ing that our pigeons successfully learned to categorize numerical arrays, we still cannot be certain that the pigeons learned something that may serve a function analogous to a series of cardinal numbers (cardination). Davis and Memmott (1982) noted that "seriation is essential for cardination" (p. 552). The question then remains whether pigeons assign each item a code of the form constituting a chain and progressively go up the chain each time they make an indicating response to an additional item in a set (see also Xia et al., 2001). Davis and Memmott noted that "cardination may generally be construed as an internal process, perhaps akin to 'counting in one's head.' Thus, at present, it is more realistic to infer the presence of cardination from successful instances of counting than vice versa" (p. 548). In this regard, it is worth examining whether, and to what extent, pigeons are able to associate the absolute number of items with something that is serial in nature or with symbols that can be learned serially. In the present study, we used four distinctive colors as the comparison stimuli. We assigned the colors to the numerosities so that the assignment of the colors to the numerosities differed from the ordering implied by the ordering of the colors, even though colors that are far apart along a color dimension are not likely to be represented serially by pigeons. We were, therefore, unable to examine integration of the two different dimensions. It would be of interest in future research to train pigeons with symbols in series and then investigate whether this initial treatment would have some benefits for pigeons' learning associations between the symbols and the numerosities.

Generalization testing in Experiment 1 provided clear evidence of ordinality. That is, the pigeons judged the novel stimuli to fall in the order $1<2<3<4<5<$ $6<7<8$. Ordinality has been usually examined in tasks that require relative judgments about differences in numerosity. For example, Emmerton et al. (1997) trained pigeons to peck one key when "few" items (one or two) were presented and to peck another key when "many" items (six or seven) were presented. Tests with intermediate arrays of three, four, or five items resulted in an orderly graded choice of the two keys. Olthof and Roberts (2000) trained pigeons to choose one of two symbols that were associated with zero, one, three, five, seven, or nine pieces of grain as rewards. The pigeons learned to choose the symbols corresponding to the larger reward and then showed transfer to novel pairs of the symbols. The finding was interpreted as suggesting that the pigeons had formed an ordinal representation of the symbols associated with the mass of the food rewards (see also Olthof \& Santi, 2007). In contrast to the previous studies that concerned judgments of relative numerousness, or more-versus-less comparisons, generalization testing with novel numerosities in the present study revealed that pigeons are indeed able to order nonfood stimuli according to the absolute number of items displayed.

The present study was not designed to examine whether pigeons learn a greater-than ordering and/or a less-than ordering and simply demonstrated that the numeral values were in an ordered sequence for pigeons. Brannon and Terrace (2000) found that rhesus monkeys successfully learned to respond to numerical stimuli (1-4) in an ascending or descending order. They could then extrapolate to new numerosities (5-9) larger than those used for training. This study demonstrated that nonverbal subjects, monkeys, are able to learn a directional ordering and transfer the learned ordering to novel numerosities. It should also be noted here that, because the numerical discrimination task in the present study relied on the associations between symbols (colored comparison stimuli) and numerosities, we were naturally unable to investigate flexible transfer to numbers outside the range of training.

From a point of view of nonverbal counting, however, the results provide a clear evidence for counting. Gallistel and Gelman (2000) argued that a nonverbal counting process represents discrete/countable quantities, as well as continuous/uncountable quantities (e.g., duration), by means of magnitudes with scalar variability (the signals encoding these magnitudes vary from trial to trial, with the width of the signal distribution increasing in proportion to its mean). In the case of countable quantities, this process repeatedly increments a magnitude that represents the current count, which defines the next magnitudes and yields a discrete ordering. The accumulation at the end of the counting represents the number of items in a set. It was argued that humans share with nonverbal animals a nonverbal counting process but only verbal subjects (adult humans) learn a mapping from magnitudes to numerals and from numerals to corresponding magnitudes. According to this model, pigeons' choice errors occur primarily due to trial-to-trial variability in the magnitudes. In the present study and Xia et al. (2001), choice errors were more likely to occur to comparison stimuli that corresponded to numerosities adjacent to the correct one, a finding consistent with scalar variability of nonverbal mental magnitudes.

Mental magnitude with scalar variability predicts Weber's law (the discriminability of two perceived magnitudes is determined by the ratio of the objective magnitudes). Pigeons' responses to the novel stimuli generally obeyed Weber's law but were affected by a procedural effect. With the novel numerosity 2 , choice 3 occurred more frequently than choice 1 . This finding appeared to meet Weber's lawthat is, discrimination between 2 and 3 is more difficult than discrimination between 1 and 2 . With the novel numerosity 4 , however, choice 3 occurred more frequently than choice 5 , a finding opposite to that predicted by Weber's law (it predicts that discrimination between 4 and 5 is more difficult than discrimination between 3 and 4). One must consider that the pigeons had performed poorly with the numerosity stimulus 5 , so that their choice 5 response was less likely to be rewarded than choice 3 and any other choice response. Note, however, that with the novel numerosity 6 , choice 5 occurred more frequently than choice 8 . This finding, as well as the finding with the novel numerosity 7 that choice 8 occurred more frequently than choice 5 , was consistent with Weber's law.

Regardless of all these considerations, the finding of Experiment 1 that pigeons can respond in an orderly manner to novel stimuli suggested that their numerical competence extends beyond the level that had been revealed by previous studies (see Emmerton, 2001, for a review). 
The subsequent experiments reported in this article have revealed that the ability demonstrated by the pigeons in Experiment 1 was not based solely on counting the absolute number of items. In contrast to other studies that controlled the surface cues by changing the size of items (e.g., Thomas et al., 1980), Experiment 2 removed some of the red dots presented at the time of choice. Imagine a situation in which peas that were pecked by a bird then rolled out of the dish and disappeared. It was observed that a decreased number of red dots increased underestimation for the large numbers 5 and 8 (Figure 2). The number of red dots and/or surface area, therefore, had some effect on the pigeons' choices (note that the present experiment was not designed to differentiate the effects of surface area and subitizing the exact number of red dots presented at the time of choice). However, the choices of the pigeons were more related to the number of white dots than to the number of red dots. In addition, subsequent training enabled the pigeons to disregard the number of red dots and related nonnumerical cues (Table 1).

Experiment 3 revealed that the pigeons were not relying on the number of white dots that could be processed or counted in parallel or on the related nonnumerical cues. This finding, together with those in Experiment 2, confirmed that the pigeons were relying primarily on the number of indicating responses and/or the temporal cue that covaried with the number of indicating responses.

Experiment 4 simulated a natural occurrence in which the pigeons had to peck several times at a rolling pea before they could grasp it, even though the items in the present experiment were not actually rolling on the monitor. It was revealed that the choice responses were more related to the number of indicating responses than to the total number of pecks or the duration of pecking. However, even after extensive training to disregard the number of pecks, the increased number of required pecks still produced overestimation for the numerosity stimuli 1 and 3 (Figure 6). It has been repeatedly demonstrated that laboratory animals simultaneously time and count stimulus sequences (e.g., Meck \& Church, 1983; Roberts, 1995). In the present study, there might be a strong inclination to time or automatically count the pecking responses that were topographically identical to the indicating response. According to the scalar-timing model of Gibbon (1977), the errors occur at the gating stage of pulse accumulation. It would be worth investigating whether this difficulty could be removed if pigeons were trained to disregard the number of pecks from the outset of training.

Fetterman (1993) noted that both the number and duration of the responses by pigeons contribute to discrimination between two fixed ratios (FR10 and FR30). He proposed that there was an ecological relevance for multiple sources of information in situations involving complex and extended stimuli (see also Fetterman, Stubbs, \& Dreyfus, 1986; Roberts \& Boisvert, 1998). Experiments 2 and 4 support this proposal. In pretest sessions of Experiments 2 and 4, the pigeons relied not only on the number, but also on other sources of information. However, an important finding in the pretest was that the pigeons relied more on the number of indicating responses than on any other confounded nonnumerical cues. That is, the present results provide evidence against the last-resort hypothesis. Pigeons effectively utilize the number of explicitly trained indicating responses even in a situation in which nonnumerical cues are available.

The ease with which our pigeons learned to categorize numerical arrays suggests that the explicitly trained indicating response facilitated the enumeration process that would otherwise have been inaccessible in natural settings. It would be of considerable interest to determine the following: whether the pigeon's indicating response explicitly trained in the present study is functionally equivalent to the voluntary movements displayed by Koehler's (1950) birds and laboratory animals with food or food-related items; whether pigeons apply their learned indicating response to novel number-related stimuli and even to a novel numerical learning context; and whether the indicating response learned by pigeons in the present study has any relationship to the origin of numerical abilities in young children. Future studies will be needed to address these issues, as well as to elucidate the fundamental mechanisms responsible for number processing in nonhuman species.

\section{AUTHOR NOTE}

This research was supported by research grants from the Japan Society for Promotion of Science to M.J. We are grateful to Tomokazu Ushitani and anonymous reviewers for their helpful comments and suggestions on an earlier version of this article. Correspondence concerning this article should be addressed to M. Jitsumori, Department of Cognitive and Information Sciences, Faculty of Letters, Chiba University, 1-33 Yayoi-cho, Inage-ku, Chiba 263-8522, Japan (e-mail: mjitsu@1.chiba-u.ac.jp).

\section{REFERENCES}

Allik, J., \& TuUlmets, T. (1991). Occupancy model of perceived numerosity. Perception \& Psychophysics, 49, 303-314.

Alsop, B., \& Honig, W. K. (1991). Sequential stimuli and relative numerosity discriminations in pigeons. Journal of Experimental Psychology: Animal Behavior Processes, 17, 386-395.

Boysen, S., Berntson, G. G., Shreyer, T. A., \& Hannan, M. B. (1995). Indicating acts during counting by a chimpanzee (Pan troglodytes). Journal of Comparative Psychology, 109, 47-51.

Brannon, E. M., \& Terrace, H. S. (2000). Representation of the numerosities 1-9 by rhesus macaques (Macaca mulatta). Journal of Experimental Psychology: Animal Behavior Processes, 26, 31-49.

Breukelaar, J. W. C., \& Dalrymple-Alford, J. C. (1998). Timing ability and numerical competence in rats. Journal of Experimental Psychology: Animal Behavior Processes, 24, 84-97.

Cantlon, J. F., \& Brannon, E. M. (2007). How much does number matter to a monkey (Macaca mulatta)? Journal of Experimental Psychology: Animal Behavior Processes, 33, 32-41.

Capaldi, E. J., \& Miller, D. J. (1988). Counting in rats: Its functional significance and the independent cognitive processes that constitute it. Journal of Experimental Psychology: Animal Behavior Processes, 14, 3-7.

CHen, C.-S. (1967). Can rats count? Nature, 214, 15-17.

Cramér, H. (1999). Mathematical methods of statistics. Princeton, NJ: Princeton University Press.

Davis, H., \& Bradford, S. A. (1986). Counting behavior by rats in a simulated natural environment. Ethology, 73, 265-280.

Davis, H., \& Memmotт, J. (1982). Counting behavior in animals: A critical evaluation. Psychological Bulletin, 92, 547-571.

DAVIS, H., \& PÉrusse, R. (1988). Numerical competence in animals: Definitional issues, current evidence, and a new research agenda. $B e$ havioral \& Brain Sciences, 11, 561-615.

Emmerton, J. (1998). Numerosity differences and effects of stimulus 
density on pigeons' discrimination performance. Animal Learning \& Behavior, 26, 243-256.

Emmerton, J. (2001). Birds' judgments of number and quantity. In R. G. Cook (Ed.), Avian visual cognition. Available at www.pigeon.psy .tufts.edu/avc/emmerton/default.htm.

Emmerton, J., Lohmann, A., \& Niemann, J. (1997). Pigeons' serial ordering of numerosity with visual arrays. Animal Learning \& Behavior, 25, 234-244.

Fernandes, D. M., \& Church, R. M. (1982). Discrimination of the number of sequential events by rats. Animal Learning \& Behavior, 10, 171-176.

Fetterman, J. G. (1993). Numerosity discrimination: Both time and number matter. Journal of Experimental Psychology: Animal Behavior Processes, 19, 149-164.

Fetterman, J. G., Stubbs, D. A., \& Dreyfus, L. R. (1986). Scaling of events spaced in time. Behavioural Processes, 13, 53-68.

Fuson, K. C. (1988). Children's counting and concepts of number. New York: Springer.

Gallistel, C. R., \& Gelman, R. (2000). Non-verbal numerical cognition: From reals to integers. Trends in Cognitive Sciences, 4, 59-65.

Gelman, R., \& Gallistel, C. R. (1978). The child's understanding of number: Cambridge, MA: Harvard University Press.

GibBon, J. (1977). Scalar expectancy theory and Weber's law in animal timing. Psychological Review, 84, 279-325.

Koenler, O. (1950). The ability of birds to "count." Bulletin of Animal Behaviour, 9, 41-45.

Matsuzawa, T. (1985). Use of numbers by a chimpanzee. Nature, $\mathbf{3 1 5}$, 57-59.

MecK, W. H., \& ChURCH, R. M. (1983). A mode control model of counting and timing processes. Journal of Experimental Psychology: Animal Behavior Processes, 9, 320-334.

Olthof, A., \& RoberTs, W. (2000). Summation of symbols by pigeons (Columba livia): The importance of number and mass of reward items. Journal of Comparative Psychology, 114, 158-166.

Olthof, A., \& SANTI, A. (2007). Pigeons (Columba livia) associate time intervals with symbols in a touch screen task: Evidence for ordinality but not summation. Journal of Comparative Psychology, 121, 82-94.

Pepperberg, I. M. (1994). Numerical competence in an African Grey parrot (Psittacus erithacus). Journal of Comparative Psychology, 108, 36-44.

Platt, J. R., \& Johnson, D. M. (1971). Localization of position within a homogeneous behavior chain: Effects of error contingencies. Learning \& Motivation, 2, 386-414.

RoBerTs, W. A. (1995). Simultaneous numerical and temporal processing in the pigeon. Current Directions in Psychological Science, 4, 47-51.

RoberTs, W. A., \& BoISVert, M. J. (1998). Using the peak procedure to measure timing and counting processes in pigeons. Journal of Experimental Psychology: Animal Behavior Processes, 24, 416-430.

RoberTs, W. A., MACUdA, T., \& BRoDBECK, D. R. (1995). Memory for number of light flashes in the pigeon. Animal Learning \& Behavior, 23, 182-188.

RoberTs, W. A., \& Mitchell, S. (1994). Can a pigeon simultaneously process temporal and numerical information? Journal of Experimental Psychology: Animal Behavior Processes, 20, 66-78.

Suzuki, K., \& Kobayashi, T. (2000). Numerical competence in rats (Rattus norvegicus): Davis and Bradford (1986) extended. Journal of Comparative Psychology, 114, 73-85.

Thomas, R. K., Fowlkes, D., \& Vickery, J. D. (1980). Conceptual numerousness judgments by squirrel monkeys. American Journal of Psychology, 93, 247-257.

Xia, L., Emmerton, J., Siemann, M., \& Delius, J. D. (2001). Pigeons (Columba livia) learn to link numerosities with symbols. Journal of Comparative Psychology, 115, 83-91.

Xia, L., Siemann, M., \& Delius, J. D. (2000). Matching of numerical symbols with number of responses by pigeons. Animal Cognition, $\mathbf{3}$, 35-43.

(Manuscript received April 23, 2009; revision accepted for publication June 29, 2009.) 